\title{
Therapeutic response and Iong-term outcome of differentiated thyroid cancer with pulmonary metastases treated by radioiodine therapy
}

\author{
Jing Yang ${ }^{1}$, Meng Liang ${ }^{1}$, Yingying Jia ${ }^{1}$, Li Wang ${ }^{1}$, Lin Lin ${ }^{1}$, Jianhua Geng ${ }^{1}$, Shengzu \\ Chen ${ }^{1}$, Ye-Xiong $\mathbf{L i}^{2}$ and Rong Zheng ${ }^{1}$ \\ ${ }^{1}$ Department of Nuclear Medicine, National Cancer Center/Cancer Hospital, Chinese Academy of Medical Sciences and Peking \\ Union Medical College, Beijing 100021, China \\ ${ }^{2}$ Department of Radiation Oncology, National Cancer Center/Cancer Hospital, Chinese Academy of Medical Sciences and \\ Peking Union Medical College, Beijing 100021, China \\ Correspondence to: Rong Zheng, email: zrong99@163.com \\ Keywords: thyroid cancer, pulmonary metastases, radioiodine therapy \\ Received: June 10,2017 Accepted: August 28, $2017 \quad$ Published: October 06, 2017 \\ Copyright: Yang et al. This is an open-access article distributed under the terms of the Creative Commons Attribution License 3.0 \\ (CC BY 3.0), which permits unrestricted use, distribution, and reproduction in any medium, provided the original author and source \\ are credited.
}

\section{ABSTRACT}

Objective: To explore the therapeutic response (TR) and long-term outcomes of iodine-131 (I-131) treatment for patients with differentiated thyroid cancer and pulmonary metastases (DTC+PM), as well as the association between the assessment of TR and long-term outcomes.

Methods: This retrospective study comprised 151 DTC+PM patients. TR was evaluated by changes in serum levels of thyroglobulin, anatomic imaging and iodine uptake in pulmonary nodules; logistic regression was applied to identify predictors. Overall survival (OS) was calculated using the Kaplan-Meier method and predictive factors of outcome by multivariate analyses.

Results: After I-131 treatment, 17 patients achieved a complete response, 71 a partial response, and 63 no response. Age, pulmonary nodule size, iodineconcentration within PM, extra-PM, frequency and cumulative dose of I-131 treatment were significant for TR. OS was $72.2 \%$ at $5,55.2 \%$ at 10 and $51.3 \%$ at 15 years. After adjustment for other factors, age, pulmonary nodule size, extra-PM, frequency and cumulative dose of I-131 treatment were significant. A significant difference of survival rate in patients with different TR group was observed.

Conclusions: There was a supportive response and prognosis for I-131 treatment upon DTC+PM patients. Older patients and those with non-I-131-avid PM were more likely to have no response to I-131 treatment, and greater benefits could be achieved by patients who complete treatment. Long-term outcome was better in patients with age $<45$ years, pulmonary nodule size $<2 \mathrm{~cm}$, without extra-PM, and the frequency of iodine treatment $\geq 5$ times. The predictive power of the TR on long-term prognosis was favorable.

\section{INTRODUCTION}

Differentiated thyroid cancer (DTC) is one of the most curable endocrine cancers and is usually associated with an excellent prognosis [1]. Distant metastases, which occur in $2.2-12.4 \%$ of patients with known DTC, are the most common cause of death in these patients [2-8]. The lungs are the most common sites of distant metastases in DTC, and patients with pulmonary metastases (PM), in general, have a poor prognosis. About $40 \%$ of DTC patients with PM die within 10 years [9]. Treatment options for DTC are surgery, radioiodine therapy (RAIT) 
and suppression of thyroid hormones, and long-term monitoring after treatment is essential [10]. Management for DTC patients with PM is based on thyroidectomy, followed by radioiodine therapy and subsequent hormonereplacement therapy [10]. RAIT has been a standard adjuvant treatment after total or near-total thyroidectomy $[11,12]$.

Several studies have reported that iodine-131 (I-131)-avid PM are curable and are associated with an excellent prognosis. In contrast, non-I-131-avid PM have a relatively poor prognosis and are associated with high thyroglobulin (Tg) levels $[9,13]$. However, few studies have clarified the factors influencing the response of I-131 treatment and the prognostic factors influencing the longterm survival for DTC patients with PM (especially for patients with I-131-avid PM)[14, 15].

The present study was designed to select DTC patients with PM for RAIT in China. Data from a clinical database on long-term follow-up for DTC patients with PM were analyzed retrospectively. We aimed to: (i) assess the therapeutic response of RAIT on DTC patients with PM; (ii) evaluate the overall survival (OS) and related variables; (iii) explore the association between the therapeutic response and long-term prognosis, and then assess if the criteria used for the assessment of therapeutic response were reliable.

\section{RESULTS}

\section{Characteristics of patients with pulmonary metastases}

The clinical characteristics of the 151 DTC patients with PM were summarized in Table 1. Among the 151 patients, 86 were women and 65 were men (male:female ratio $=1: 1.32$ ) and $73.5 \%$ had PTC. PM alone were involved in 124 patients, whereas 27 patients also had metastases to other organs. All 151 patients underwent thyroidectomy: 82 patients received unilateral total and contralateral subtotal thyroidectomy first and then underwent a second procedure to remove remaining thyroid tissue; total thyroidectomy was done as the primary procedure in 69 cases. I-131-avid PM were observed in 122 patients and non-I-131-avid PM were found in 29 patients. Of the 151 patients diagnosed with PM, 77 patients had a cumulative dose $19.6 \mathrm{GBq}(530 \mathrm{mCi}) \mathrm{mCi}$ whereas the others had doses $<19.6 \mathrm{GBq}(530 \mathrm{mCi})$.

\section{Therapeutic response and influencing factors}

The therapeutic response of 151 DTC patients with PM to RAIT was shown in Table 1. Of the 151 patients, 17 achieved a CR (11.3\%), 71 PR (47.0\%) and 63 NR (41.7\%). Age, capsule invasion, metastases type, Tg level, iodine concentration within PM, extra-PM, and the cumulative dose of 131-I treatment in the three therapeutic-response groups were significantly different $(\mathrm{P}$ $<0.001,0.016,0.002,0.010,<0.001,0.015$, and 0.010, respectively).

Univariate logistic regression analyses of the factors influencing the therapeutic response were shown in Table 2. Differences in age, size of pulmonary nodules, iodine concentration within PM, extra-PM, frequency and the cumulative dose of I-131 treatment were significant (P<0.001, 0.032, < 0.001, 0.016, 0.018, and 0.003, respectively). Age $<45$ years and I-131-avid PM had the most favorable effect on therapeutic response, and the relative ratios were 9.28 (95\% confidence interval (CI): 4.15-20.71) and 13.82 (95\% CI: 4.50-42.47), respectively.

\section{Survival and prognostic survival factors}

OS from the diagnoses of PM were shown in Figure 1. Prognostic survival factors were listed in Table 3. Median survival of the 151 patients was 9.6 years, and OS was $72.2 \%$ at 5 years, $55.2 \%$ at 10 years and $51.3 \%$ at 15 years, respectively. OS at 10 years was $90.9 \%$ in patients aged $<45$ years and $18.8 \%$ in patients aged $\geq 45$. For patients with PM only, survival at 10 years was $65.1 \%$, which was significantly higher than patients with extraPM (9.1\%). OS at 10 years was $78.8 \%$ in patients with micro-nodular metastases $(<1 \mathrm{~cm})$ and $27.7 \%$ in those with macro-nodular metastases $(\geq 1 \mathrm{~cm})$.

For all 151 patients, univariate analyses showed that remarkably poor survival outcomes were associated with patients: aged $\geq 45$ years; with FTC; with macronodular metastases; with non-I-131-avid PM; with capsule invasion; with extra-PM; who had undergone I-131 treatment frequency fewer than five times or who had a cumulative dose $<530 \mathrm{mCi}$. After adjustment for other significant factors, Cox's regression analyses showed that age, size of pulmonary nodules, combination with extraPM, frequency of I-131 treatment remained significant for survival $(\mathrm{P}<0.001,0.018,0.007$ and 0.002 , respectively) (Figure 2).

\section{Patients with I-131 avid pulmonary metastases and their predictive factors}

I-131 non-avid PM was the most predictable variable for a poor outcome. Hence, we extracted all 122 patients with I-131-avid PM and a subset analysis of therapeutic response as well as survival outcome was conducted to determine which factors contributed to the outcome of I-131 treatment for DTC patients with I-131avid PM.

For all 122 patients with I-131-avid PM, the associations between therapeutic response and age and extra-PM remained significant $(\mathrm{P}<0.001$ and 0.007 , respectively) whereas the other factors were no longer 
Table 1: Clinical characteristics of patients with differentiated thyroid cancer and pulmonary metastases and the response to radioiodine therapy

\begin{tabular}{|c|c|c|c|c|c|}
\hline Factor & $\begin{array}{l}\text { No. of patients } \\
\text { No. }(\%)\end{array}$ & CR & PR & NR & $\mathbf{P}$ \\
\hline Sex & & & & & 0.634 \\
\hline Male & $65(43.0)$ & 7 & 28 & 30 & \\
\hline Female & $86(57.0)$ & 10 & 43 & 33 & \\
\hline Age at PM diagnosis (years) & & & & & $<0.001$ \\
\hline$<45$ & $66(43.7)$ & 13 & 43 & 10 & \\
\hline$\geq 45$ & $85(56.3)$ & 4 & 28 & 53 & \\
\hline Pathology & & & & & 0.727 \\
\hline PTC & $111(73.5)$ & 14 & 52 & 45 & \\
\hline FTC & $40(26.5)$ & 3 & 19 & 18 & \\
\hline Capsule invasion & & & & & 0.016 \\
\hline Yes & $66(43.7)$ & 5 & 27 & 34 & \\
\hline No & $9(6.0)$ & 1 & 8 & 0 & \\
\hline Unknown & $76(50.3)$ & 11 & 36 & 29 & \\
\hline Pulmonary nodule size $(\mathrm{cm})$ & & & & & 0.055 \\
\hline$<1$ & $67(44.4)$ & 12 & 35 & 20 & \\
\hline$\geq 1$ & $46(30.4)$ & 3 & 19 & 24 & \\
\hline Unknown & $38(25.2)$ & 2 & 17 & 19 & \\
\hline PM type & & & & & 0.002 \\
\hline Diffuse & $131(86.7)$ & 10 & 67 & 54 & \\
\hline Focal & $14(9.3)$ & 6 & 3 & 5 & \\
\hline Unknown & $6(4.0)$ & 1 & 1 & 4 & \\
\hline Tg level & & & & & 0.010 \\
\hline High $(>10$ mg/L) & $112(74.2)$ & 8 & 59 & 45 & \\
\hline $\operatorname{Normal}(\leqq 10 \mathrm{mg} / \mathrm{L})$ & $39(25.8)$ & 9 & 12 & 18 & \\
\hline Iodine concentration within PM & & & & & $<0.001$ \\
\hline Yes & $122(80.8)$ & 17 & 67 & 38 & \\
\hline No & $29(19.2)$ & 0 & 4 & 25 & \\
\hline Extra-PM & & & & & 0.015 \\
\hline Yes & $27(17.9)$ & 0 & 10 & 17 & \\
\hline No & $124(82.1)$ & 17 & 61 & 46 & \\
\hline Frequency of I-131 treatment & & & & & 0.053 \\
\hline$<5$ & $96(63.6)$ & 10 & 39 & 47 & \\
\hline$\geq 5$ & $55(36.4)$ & 7 & 32 & 16 & \\
\hline Cumulative dose (mCi) & & & & & 0.010 \\
\hline$<530$ & $74(49.0)$ & 7 & 27 & 40 & \\
\hline$\geq 530$ & $77(51.0)$ & 10 & 44 & 23 & \\
\hline Radiotherapy or chemotherapy & & & & & 0.105 \\
\hline Yes & $30(19.9)$ & 4 & 9 & 17 & \\
\hline No & $121(80.1)$ & 13 & 62 & 46 & \\
\hline
\end{tabular}

CR: complete response; PR: partial response; NR: no response; PTC: papillary thyroid carcinoma; FTC: follicular thyroid carcinoma; Tg: thyroglobulin; PM: pulmonary metastases. 
Table 2: Univariate analyses of the therapeutic response and influencing factors in 151 patients with differentiated thyroid cancer and pulmonary metastases

\begin{tabular}{|c|c|c|c|c|c|}
\hline Factor & No. of patients & OR & NR & $\mathbf{P}$ & Relative ratio $(95 \% \mathrm{CI})$ \\
\hline Age at PM diagnosis (years) & & & & $<0.001$ & $9.28(4.15-20.71)$ \\
\hline$\geq 45$ & 85 & 32 & 53 & & \\
\hline$<45$ & 66 & 56 & 10 & & \\
\hline Pulmonary nodule size $(\mathrm{cm})$ & & & & 0.032 & \\
\hline Unknown & 38 & 19 & 19 & 0.042 & $2.35(1.03-5.35)$ \\
\hline$\geq 1$ & 46 & 22 & 24 & 0.018 & $2.56(1.18-5.59)$ \\
\hline$<1$ & 67 & 47 & 20 & & \\
\hline Iodine concentration within PM & & & & $<0.001$ & $13.82(4.50-42.47)$ \\
\hline No & 29 & 4 & 25 & & \\
\hline Yes & 122 & 84 & 38 & & \\
\hline Extra-PM & & & & 0.016 & $2.88(1.22-6.83)$ \\
\hline Yes & 27 & 10 & 17 & & \\
\hline No & 124 & 78 & 46 & & \\
\hline Frequency of I-131 treatment & & & & 0.018 & $2.34(1.15-4.74)$ \\
\hline$<5$ & 96 & 49 & 47 & & \\
\hline$\geq 5$ & 55 & 39 & 16 & & \\
\hline Cumulative dose (mCi) & & & & 0.003 & $2.76(1.42-5.39)$ \\
\hline$<530$ & 74 & 34 & 40 & & \\
\hline$\geq 530$ & 77 & 54 & 23 & & \\
\hline
\end{tabular}

OR: overall response; NR: no response; PM: pulmonary metastases.

significant. As expected, the estimate of Cox's regression model showed a similar pattern for all 151 DTC patients, and the hazard ratios were slightly different from the predicted age (8.55 to 10.46 ), size of pulmonary nodules (2.58 to 3.14), extra-PM (2.11 to 2.17 ) and frequency of I-131 treatment (2.55 to 3.12) (Table 3 and Table 4).

\section{Association of the therapeutic response and long- term prognosis}

We wished to: (i) evaluate the criteria for assessment of the therapeutic response for DTC patients with PM; (ii) discover if an assessment of therapeutic response during I-131 treatment could modify these initial risk estimates. Hence, two targeted survival analyses were carried out (Figure 3).

For all 151 DTC patients with PM, OS at 15 years for the 17 patients with a CR was $100 \%$. In contrast, OS was $72.4 \%$ for the 71 patients with a PR and $0 \%$ for the
63 patients with NR. A similar pattern was observed for the 122 patients with I-131-avid PM, patients with a CR had a better prognosis than those with a PR, whereas the worst prognosis was observed in the 38 patients with NR. All differences among the three groups were significant $(\mathrm{P}<0.001)$.

\section{DISCUSSION}

In this retrospective study of 151 DTC patients with PM, $11.3 \%$ and $47.0 \%$ patients achieved a CR and PR, respectively. Results suggested that older and patients with non-I-131-avid PM were more likely to show no response to initial I-131 treatment, and that greater benefits could be achieved by patients with I-131-avid PM who adhered to completion of I-131 treatment. 70 patients died during the follow-up period, and 81 patients survived or were lost to follow-up, resulting in OS at 5, 10 and 15 years of $72.2 \%$, 
$55.2 \%$ and $51.3 \%$ respectively. Multivariate analyses showed that better long-term outcome was related to: (i) clinical factors (age at the diagnosis of $\mathrm{PM}<45$ years, size of $\mathrm{PM}<2 \mathrm{~cm}$, without extra-PM); (ii) treatment factors (frequency or the cumulative dose of I-131 treatment $\geq 5$ times). In addition, there were significant differences ( $P$ $<0.001$ ) in long-term OS among patients with different therapeutic responses.

Only $58.3 \%$ patients achieved a CR or PR, which was lower than that reported in other studies using identical criteria in China [9, 14, 16-18]. The reason underlying this low prevalence for a CR may have been: (i) more than half of patients were aged $\geq 45$ years; (ii) $92.7 \%$ of patients were diagnosed with PM by anatomic imaging; (iii) most patients (85/151) were diagnosed as having advanced DTC according to the NCCN (National Comprehensive Cancer Network) guidelines.

OS was consistent with that in a study in Shanghai (China)[9], higher than that in studies undertaken in western countries $[19,20]$, and lower than that in other Asian studies [3,21]. Early diagnosis of thyroid cancer in Asia (especially in South Korea and China) in recent years could explain the favorable long-term prognosis in Asian countries $[22,23]$.

One of the main aims of this study was to evaluate the criteria for assessment of the therapeutic response for DTC patients with PM, as excepted, a supportive result was observed. Survival analyses showed significant differences $(\mathrm{P}<0.001)$ in long-term survival among patients with different therapeutic responses. Patients who had a CR had better prognosis than those who had a $\mathrm{PR}$, whereas the worst prognosis was observed for those with a NR. In our study, the change in serum levels of Tg and anatomic imaging were considered to be cooperative prognostic indicators for assessment of the response to I-131 treatment for PM. Numerous studies have been done on the prognostic value for disease-free remission and death of DTC patients [24-26]. It is thought that the serum level of Tg under TSH increase $(>30 \mathrm{uIU} / \mathrm{ml})$ is the most reliable indicator for persistent/recurrent disease and remission, and smaller nodules in anatomic imaging is related to a favorable response to I-131 treatment [9, 14, 16-18]. Given those facts, the criteria for assessment of the therapeutic response for DTC patients with PM was acceptable and the predictive power of the TR on longterm prognosis was favorable.

Age has been demonstrated to predict the response and mortality risk of I-131 treatment in DTC patients with PM $[9,13,17]$. We also found age to be a significant predictor, with a risk of NR increasing $6.0 \%$ per year. After adjustment for pulmonary nodule size, extra-PM, and the frequency of I-131 treatment, the mortality risk in DTC patients with PM increased by $6.3 \%$ per year. This result was consistent with those of Huang et al.,[3]

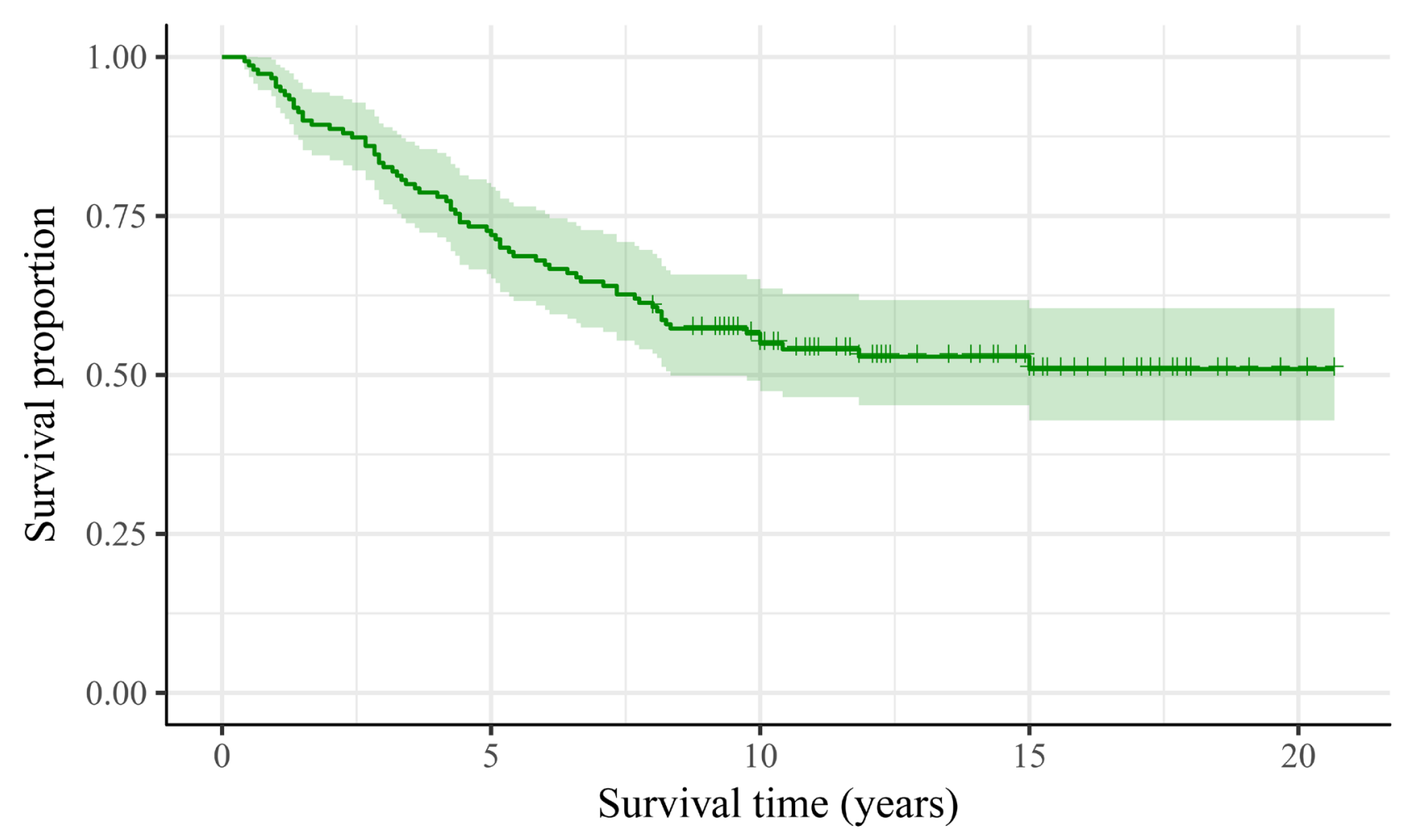

Figure 1: Survival curves form the diagnoses of pulmonary metastases for 151 patients with differentiated thyroid cancer and pulmonary metastases. 
Table 3: Univariate and multivariate survival analyses for 151 patients with differentiated thyroid cancer and pulmonary metastases

\begin{tabular}{|c|c|c|c|c|c|c|c|}
\hline Factor & $\begin{array}{c}\text { No. of } \\
\text { patients }\end{array}$ & $\begin{array}{c}\text { 5-year } \\
\text { OS }(\%)\end{array}$ & $\begin{array}{l}\text { 10-year } \\
\text { OS }(\%)\end{array}$ & 15-year OS (\%) & Univariate $\mathbf{P}$ & Multivariate $\mathbf{P}$ & Hazard ratio (95\% CI) \\
\hline $\begin{array}{l}\text { Age at PM } \\
\text { diagnosis }\end{array}$ & & & & & $<0.001$ & $<0.001$ & $8.55(3.53-20.73)$ \\
\hline$\geq 45$ & 85 & 31.6 & 18.8 & 18.8 & & & \\
\hline$<45$ & 66 & 92.4 & 90.9 & 90.9 & & & \\
\hline Pathology & & & & & $<0.001$ & & \\
\hline PTC & 111 & 79.3 & 64.4 & 58.8 & & & \\
\hline FTC & 40 & 52.5 & 29.8 & 29.8 & & & \\
\hline Capsule invasion & & & & & 0.007 & & \\
\hline Unknown & 76 & 73.7 & 61.8 & 60.1 & & & \\
\hline No & 9 & 88.9 & 88.9 & 88.9 & & & \\
\hline Yes & 66 & 66.7 & 46.4 & 34.5 & & & \\
\hline $\begin{array}{l}\text { Pulmonary nodule } \\
\text { size }(\mathrm{cm})\end{array}$ & & & & & $<0.001$ & 0.018 & \\
\hline Unknown & 38 & 65.8 & 47.1 & 43.4 & & 0.045 & $2.00(1.02-3.95)$ \\
\hline$\geq 1$ & 46 & 56.5 & 27.7 & 24.6 & & 0.005 & $2.58(1.34-4.98)$ \\
\hline$<1$ & 67 & 86.6 & 78.8 & 73.9 & & & \\
\hline $\begin{array}{l}\text { Iodine } \\
\text { concentration in } \\
\text { PM }\end{array}$ & & & & & 0.007 & & \\
\hline Yes & 122 & 74.6 & 60.3 & 55.9 & & & \\
\hline No & 29 & 62.1 & 33.2 & 33.2 & & & \\
\hline Extra-PM & & & & & $<0.001$ & 0.007 & $2.11(1.23-3.63)$ \\
\hline Yes & 27 & 40.7 & 9.3 & 0 & & & \\
\hline No & 124 & 79.0 & 65.1 & 65.1 & & & \\
\hline $\begin{array}{l}\text { Frequency of I-131 } \\
\text { treatment }\end{array}$ & & & & & $<0.001$ & 0.002 & $2.55(1.40-4.63)$ \\
\hline$<5$ & 96 & 61.5 & 44.4 & 42.6 & & & \\
\hline$\geq 5$ & 55 & 90.9 & 74.1 & 67.2 & & & \\
\hline $\begin{array}{l}\text { Cumulative dose } \\
\text { (mCi) }\end{array}$ & & & & & 0.003 & & \\
\hline$<530$ & 74 & 60.8 & 44.2 & 41.3 & & & \\
\hline$\geq 530$ & 77 & 83.1 & 65.8 & 60.9 & & & \\
\hline $\begin{array}{l}\text { Therapeutic } \\
\text { response }\end{array}$ & & & & & $<0.001$ & & \\
\hline $\mathrm{CR}$ & 17 & 100.0 & 100.0 & 100.0 & & & \\
\hline PR & 71 & 83.1 & 74.4 & 72.4 & & & \\
\hline NR & 63 & 52.4 & 21.2 & 0.0 & & & \\
\hline
\end{tabular}

OS: overall survival; CR: complete response; PR: partial response; NR: no response; PTC: papillary thyroid carcinoma; FTC: follicular thyroid carcinoma; PM: pulmonary metastases. 
Schlumberger et al., [27] and Ruegemer et al.,[28] with mortality risk increasing by $5.6 \%, 4 \%$ and $7 \%$ per year, respectively.

The size of pulmonary lesions (macro- or micronodules) was an important prognostic factor. Favorable long-term outcomes were observed for patients with smaller metastases. Macro-nodular metastases showed poor iodine concentration within PM (14/46, 30.4\%) and poor OS. Song et al.[9] showed that micro-nodular metastases were susceptible to I-131 treatment and had a good prognosis, whereas macro-nodular metastases of non-I-131-avid nodules had a poor prognosis. The prevalence of a CR for DTC patients with PM undetected by $\mathrm{CT}$ of the chest was $23.8 \%$ and the OR was $95.2 \%$ [8], which were higher than those of studies involving CTbased diagnoses of patients [9, 14, 16-18]. This result may have been because patients with larger nodules are more likely to have a later stage of DTC, a poorer concentration of iodine within metastases, and only a small number of patients are cured $[8,9]$.

PTC was more common than FTC in patients with PM. However, FTC was shown to have a negative impact on long-term survival for DTC patients with PM, as demonstrated by other scholars [17, 29].
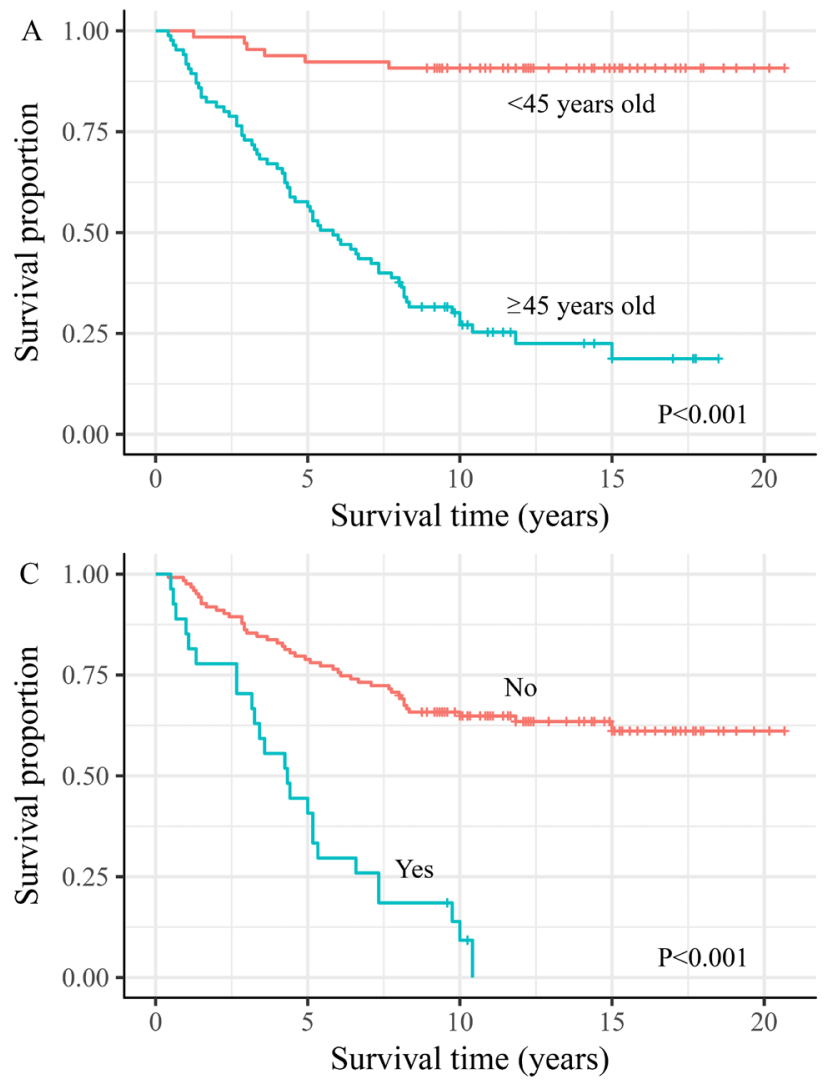

FTC is an aggressive type of malignancy and several extra-pulmonary organs or sites can be invaded by hematogenous metastases. Extensive researches suggested that FTC is prone to distant metastases compared with PTC $[8,17]$.

The difference in long-term outcome between patients with pulmonary-only metastases and those with extra-PM was significant $(\mathrm{P}<0.001)$. Studies have shown that bone metastases have a worse curative effect than that of PM with regard to I-131 treatment in DTC patients with PM $[15,20]$. This difference may be because I-131 treatment results in a better prognosis for DTC patients with PM than those for patients with bone metastases or other distant metastases [15, 29], and multiple metastases often demonstrate advanced thyroid cancer.

The long-term prognosis of patients with iodine concentration within PM was better than those without iodine concentration within PM. Non-I-131-avid metastases often demonstrate dedifferentiated thyroid cancer cells, which is accompanied by reduced expression of the sodium iodide symporter, the TSH receptor, and thyroid peroxidase [30-32]. Several studies have shown very limited benefit by RAIT in patients with non-I-131avid pulmonary disease $[20,21,33]$.
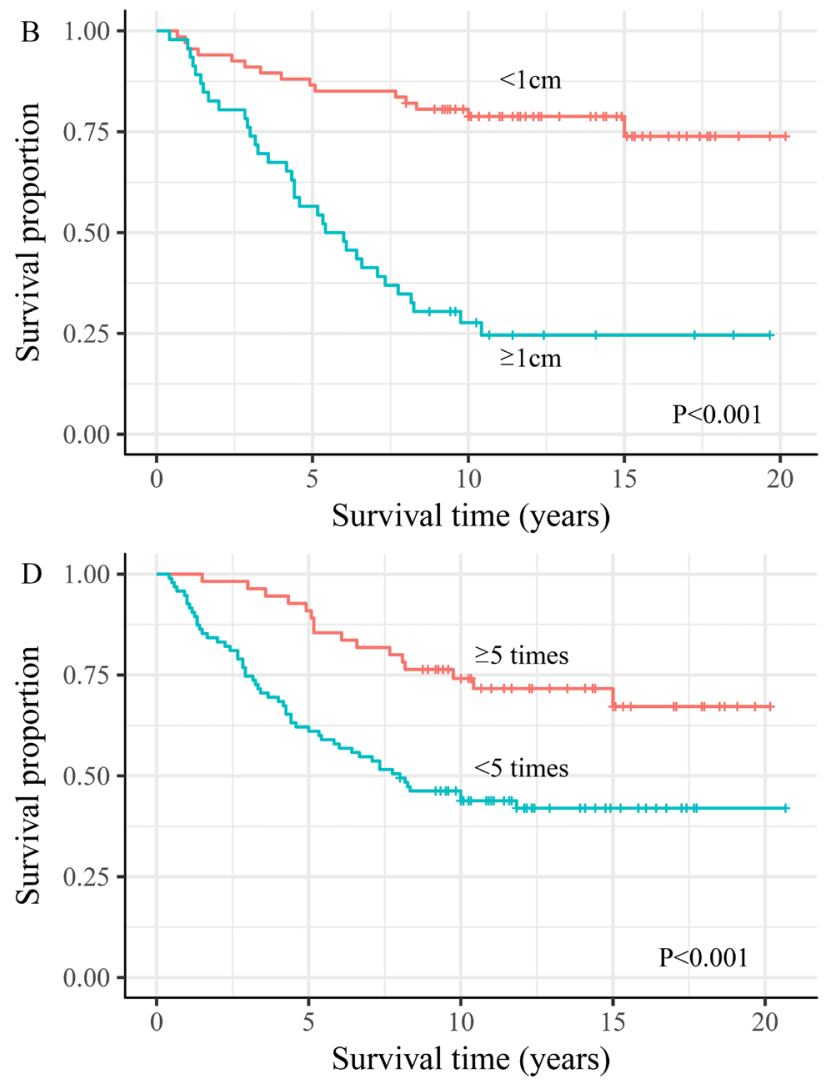

Figure 2: Overall survival time from diagnosis of pulmonary metastases for the differentiated thyroid cancer with pulmonary metastasis patients by (A) age at diagnosis of metastasis, (B) pulmonary nodules size, (C) extra pulmonary metastasis, and (D) frequency of I-131 treatment. 
Table 4: Univariate and multivariate survival analyses for 122 differentiated thyroid cancer patients with I-131-avid pulmonary metastases

\begin{tabular}{|c|c|c|c|c|c|c|c|}
\hline Factors & $\begin{array}{c}\text { No. of } \\
\text { patients }\end{array}$ & $\begin{array}{c}\text { 5-year } \\
\text { OS (\%) }\end{array}$ & 10-year OS (\%) & 15-year OS (\%) & Univariate $P$ & Multivariate $\mathbf{P}$ & $\begin{array}{c}\text { Hazard ratio } \\
(95 \% \mathrm{CI})\end{array}$ \\
\hline Age at PM diagnosis (years) & & & & & $<0.001$ & $<0.001$ & $10.46(3.94-27.74)$ \\
\hline$\geq 45$ & 60 & 55.00 & 27.5 & 18.7 & & & \\
\hline$<45$ & 62 & 93.50 & 91.9 & 91.9 & & & \\
\hline Pathology & & & & & $<0.001$ & & \\
\hline PTC & 87 & 82.20 & 70.9 & 69.1 & & & \\
\hline FTC & 35 & 53.10 & 30.9 & 17.7 & & & \\
\hline Capsule invasion & & & & & 0.006 & & \\
\hline Unknown & 76 & 76.6 & 67.2 & 65.3 & & & \\
\hline No & 9 & 100.0 & 100.0 & 100.0 & & & \\
\hline Yes & 66 & 68.6 & 45.5 & 36.5 & & & \\
\hline Pulmonary nodule size & & & & & $<0.001$ & 0.016 & \\
\hline Unknown (cm) & 32 & 65.60 & 50.0 & 45.8 & & 0.087 & $1.95(0.91-4.21)$ \\
\hline$\geq 1$ & 32 & 56.30 & 33.8 & 29.5 & & 0.004 & $3.14(1.44-6.88)$ \\
\hline$<1$ & 58 & 89.70 & 80.7 & 75.7 & & & \\
\hline Extra-PM & & & & & $<0.001$ & 0.015 & $2.17(1.16-4.04)$ \\
\hline Yes & 21 & 38.10 & 9.5 & 0 & & & \\
\hline No & 101 & 82.20 & 71.2 & 67.2 & & & \\
\hline Frequency of I-131 treatment & & & & & 0.002 & 0.001 & $3.12(1.58-6.18)$ \\
\hline$<5$ & 69 & 60.9 & 49.0 & 46.9 & & & \\
\hline$\geq 5$ & 53 & 92.5 & 75.1 & 68.0 & & & \\
\hline Cumulative dose (mCi) & & & & & 0.007 & & \\
\hline$<530$ & 50 & 60.00 & 47.5 & 43.9 & & & \\
\hline$\geq 530$ & 72 & 84.70 & 69.2 & 64.1 & & & \\
\hline Therapeutic response & & & & & $<0.001$ & & \\
\hline $\mathrm{CR}$ & 17 & 100.0 & 100.0 & 100.0 & & & \\
\hline PR & 67 & 82.1 & 74.3 & 72.3 & & & \\
\hline NR & 38 & 50.0 & 17.5 & 0.0 & & & \\
\hline
\end{tabular}

OS: overall survival; CR: complete response; PR: partial response; NR: no response; PTC: papillary thyroid carcinoma; FTC: follicular thyroid carcinoma; PM: pulmonary metastases.
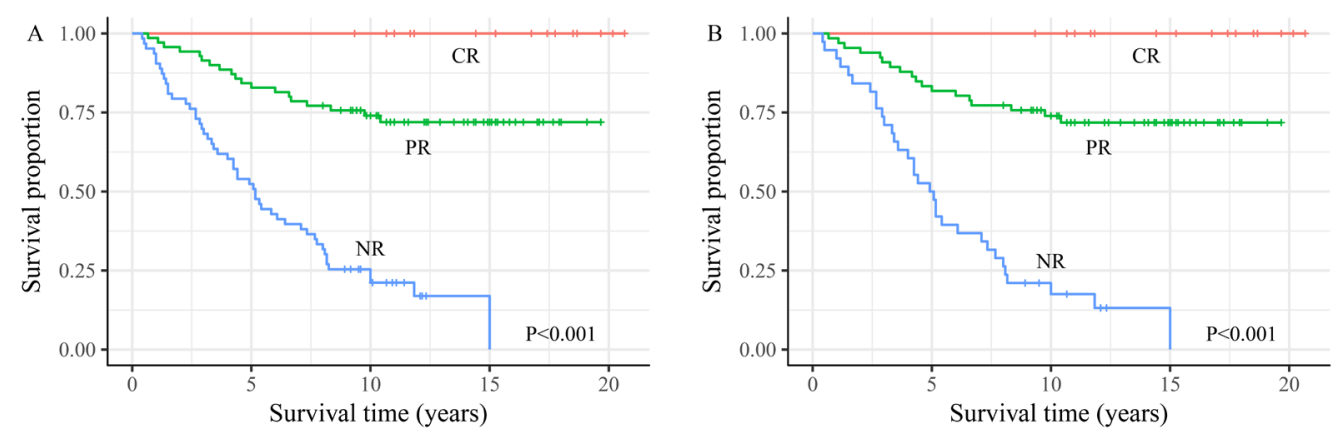

Figure 3: The survival analysis of differentiated thyroid cancer with pulmonary metastasis patients for three initial therapy risk response groups involved in (A) all 151 differentiated thyroid cancer with pulmonary metastases patients and (B) 122 I-131-avid patients. 
For all 151 patients, having I-131 treatment $\geq 5$ occasions or a cumulative dose $\geq 530 \mathrm{mCi}$ elicited a better therapeutic response and long-term outcome. Our result might have been because patients with non-I-131-avid PM usually resorted to other treatment options. Only $6.9 \%$ of patients had more than five courses of I-131 treatment, which resulted in poor long-term outcomes in those patients. We further analyzed the survival prognostic factors of 122 patients with I-131-avid metastases separately; univariate and multivariate analyses were consistent with the results of the analyses of all 151 patients. This observation suggested that I-131 treatment was beneficial for the long-term outcome of DTC patients with PM, and that patients with I-131-avid metastases should complete all courses of treatment.

Our study had several limitations. First, because it was retrospective and included only those DTC patients treated by RAIT in a single center in China, the results might be derived from a biased patient group. Second, during the long study period, small portion of clinical data were missing, which might have caused bias in data selection. Third, the pathologic diagnosis of PM was not always available, so it was diagnosed based on imaging and increased serum levels of $\mathrm{Tg}$. However, the detection of thyroglobulin antibody $(\mathrm{TgAb})$ was not always available in study period in our hospital, this may potentially affect the accurate evaluation of therapeutic response. In addition, we could not completely rule out the possibility of other conditions, such as incidental primary lung cancers or benign lung disorders such as inflammation.

Despite these limitations, the results of this study may have important clinical implications. These data suggested that older patients and those with non-I-131avid PM were more likely to have NR to initial I-131 treatment. Also, greater benefits could be achieved upon completion of I-131 treatment for DTC patients with I-131-avid PM. Long-term outcome was related to age, the size of PM, whether PM were accompanied by other distant metastases, and the frequency of RAIT. Moreover, by accessing the therapeutic response to I-131 therapy, clinicians can have an insight into the long-term prognosis for DTC patients with PM. All of these may be helpful to guide clinical treatment for DTC with PM patients.

\section{MATERIALS AND METHODS}

\section{Patient eligibility}

This retrospective cohort yielded 151 DTC with PM patients at the department of nuclear medicine between February 1991 and July 2007. The median ages at the diagnosis of DTC and PM were 42 (range, 6-82) and 49 (range, 11-86) years, respectively. One-hundred and eleven patients were diagnosed as having papillary thyroid carcinoma (PTC) and 40 patients as having follicular thyroid carcinoma (FTC). PM only were involved in 124 patients, whereas 27 patients also had distant metastases to other organs.

\section{Diagnostic of DTC pulmonary metastases}

A patient satisfying the following criteria was considered to have PM: (i) pathology results confirming PM; (ii) I-131 whole-body scan (I-131-WBS) demonstrating iodine concentration within unilateral lung or bilateral lungs; (iii) positive anatomic imaging (radiography, computed tomography (CT) of the chest).

\section{I-131 Treatment protocols and evaluation of therapeutic response}

All 151 patients underwent thyroidectomy. Neck dissection was undertaken if any lymph node was enlarged and malignancy was suspected according to preoperative imaging or physical examination. All patients were instructed to follow a low-iodine diet for $\geq 2$ weeks. During the 3-4 weeks before the start of I-131 treatment, all patients were forbidden to take any iodine or iodine substance, and withdrawal of thyroid hormones had achieved a sufficient hypothyroid state (serum level of thyroid-stimulating hormone $(\mathrm{TSH})>30$ $\mathrm{uIU} / \mathrm{ml}$. Conventional measurements, including those for free tri-iodothyronine, free thyroxine, $\mathrm{TSH}, \mathrm{Tg}$, neck ultrasonography and $\mathrm{CT}$ of the chest, were done before I-131 administration. All 151 patients were treated with thyroid hormone therapy from the day after I-131 treatment. I-131-WBS was carried out 7 days after oral administration of I-131 to observe I-131 uptake by PM. After surgery, all patients received one dose of 2.96-5.55 GBq ( $80-150$ mCi) RAIT (median dose was $3.70 \mathrm{GBq}$, dose was halved for children) to remove residual thyroid tissue. The therapeutic dose was based on a fixed dose method combined with maximum dose experience, a single dose of RAIT for PM was 2.96-7.4 GBq (80-200 $\mathrm{mCi})$ with the median dose of $5.55 \mathrm{GBq}(150 \mathrm{mCi})$, and the median cumulative RAIT dose was $19.6 \mathrm{GBq}$ $(530 \mathrm{mCi})$. The indication of stopping treatment in nonI-131-avid PM was as follow: after the low iodine diet and elevating thyroid stimulating hormone TSH, the WBS imaging after RAI treatment showed that the lung metastasis did not take iodine, and the lung metastasis in $\mathrm{CT}$ imaging increased or enlarged.

Based on imaging (including WBS) and serum levels of $\mathrm{Tg}$ [8], therapeutic response was classified as: (i) complete response (CR) - no symptoms of PM, no abnormal concentration of iodine within PM upon I-131-WBS or other imaging examinations, and $\mathrm{Tg}$ negativity (serum $\mathrm{Tg}<1 \mathrm{ng} / \mathrm{mL}$ with TSH stimulation); (ii) partial response (PR) - concentration of iodine within PM reduced in I-131-WBS and metastatic pulmonary nodules were smaller or less in other imaging 
examinations, with reduced Tg levels (compared with inhibition or stimulation of $\mathrm{TSH}$ ). (iii) no response (NR) - no improvement or increased concentration of iodine within PM and no change or enlargement or more of metastatic pulmonary nodules in other imaging examinations, with increased Tg levels. The overall response (OR) was CR plus PR.

\section{Follow-up and statistical analyses}

All patients were observed at follow-up even if they were admitted to other departments or hospitals. Patients who completed the entire treatment in our hospital were followed up at outpatient clinics annually for first 5 years and then every 2 or 3 years. Patients transferred to other hospitals were followed up by telephone. This was a study looking at long-term outcome, so all patients had been followed up $\geq 5$ years after the diagnosis of metastases. Median follow-up was 11.2 (range, 0.4-20.5) years. Statistical analyses were undertaken on follow-up data collected up to September 2015 or at the time of death resulting from any cause. OS was calculated from the initial diagnosis of PM until the time of death resulting from any cause or until the final follow-up assessment.

The chi-square or Fisher's exact test was used to estimate the differences between groups. A binary logistic regression model was fitted to assess which factors contributed to the outcome of response to I-131 treatment. Kaplan-Meier survival analyses were applied to evaluate the effect of each potential prognostic variable on survival, and the differences between groups were compared using the log-rank test. Multivariate analyses were done with a Cox proportional hazards model to assess the relationship between survival time and several variables simultaneously. The patients were divided into three groups according to their therapeutic responses, after long-term follow-up, the differences of survival curves in 3 groups were tested to access whether the evaluation of the therapeutic response was reliable. $\mathrm{P}<0.05$ was considered significant. Data were analyzed using R v3.2.5 (R Foundation for Statistical Computing).

\section{Abbreviations}

TR: therapeutic response; PM: pulmonary metastases; OS: overall survival; DTC: differentiated thyroid cancer; RAIT: radioiodine therapy; $\mathrm{Tg}$ : thyroglobulin; PTC: papillary thyroid carcinoma; FTC: follicular thyroid carcinoma; CT: computed tomography; WBS: whole-body scan; TSH: thyroid-stimulating hormone; CR: complete response; PR: partial response; NR: no response; OR: overall response; $\mathrm{CI}$ : confidence interval; TgAb: thyroglobulin antibody.

\section{Author contributions}

Rong Zheng conceived and designed the study; Jing Yang performed the statistical analysis, created the first draft of the manuscript and revised the draft under the guidance of Rong Zheng; Meng Liang undertook follow-up and collected data; Yin-Yin Jia, Li Wang and Lin Lin diagnosed and selected the patients; Jian-Hua Geng, Sheng-Zu Chen and Ye-Xiong Li gave constructive suggestions for writing of the manuscript. All authors contributed to and approved the final version of the manuscript.

\section{ACKNOWLEDGMENTS}

We thank Huntington Beach for editorial assistance.

\section{CONFLICTS OF INTEREST}

The authors declare no conflicts of interest.

\section{FUNDING}

This work was supported by the National Key Projects of Research and Development of China [grant number 2016YFC0904600].

\section{REFERENCES}

1. Zeng H, Zheng R, Guo Y, Zhang S, Zou X, Wang N, Zhang L, Tang J, Chen J, Wei K, Huang S, Wang J, Yu L, et al. Cancer survival in China, 2003-2005: a populationbased study. Int J Cancer. 2015; 136:1921-30. https://doi. org/10.1002/ijc.29227.

2. Goffredo P, Sosa JA, Roman SA. Differentiated thyroid cancer presenting with distant metastases: a population analysis over two decades. World J Surg. 2013; 37:1599605. https://doi.org/10.1007/s00268-013-2006-9.

3. Huang IC, Chou FF, Liu RT, Tung SC, Chen JF, Kuo MC, Hsieh CJ, Wang PW. Long-term outcomes of distant metastasis from differentiated thyroid carcinoma. Clin Endocrinol (Oxf). 2012; 76:439-47. https://doi. org/10.1111/j.1365-2265.2011.04231.x.

4. Lang BH, Wong KP, Cheung CY, Wan KY, Lo CY. Evaluating the prognostic factors associated with cancerspecific survival of differentiated thyroid carcinoma presenting with distant metastasis. Ann Surg Oncol. 2013; 20:1329-35. https://doi.org/10.1245/s10434-012-2711-x.

5. Lee J, Soh EY. Differentiated thyroid carcinoma presenting with distant metastasis at initial diagnosis clinical outcomes and prognostic factors. Ann Surg. 2010; 251:114-9. https:// doi.org/10.1097/SLA.0b013e3181b7faf6.

6. Li YR, Chen ST, Hseuh C, Chao TC, Ho TY, Lin JD. Risk factors of distant metastasis in the follicular variant of 
papillary thyroid carcinoma. J Formos Med Assoc. 2016; 115:665-71. https://doi.org/10.1016/j.jfma.2015.07.002.

7. Lin JD, Hsueh C, Chao TC. Long-term follow-up of the therapeutic outcomes for papillary thyroid carcinoma with distant metastasis. Medicine (Baltimore). 2015; 94:e1063. https://doi.org/10.1097/md.033240R1033240R11063.

8. Long B, Yang M, Yang Z, Yi H, Li L. Assessment of radioiodine therapy efficacy for treatment of differentiated thyroid cancer patients with pulmonary metastasis undetected by chest computed tomography. Oncol Lett. 2016; 11:965-8. https://doi.org/10.3892/ol.2015.4034.

9. Song HJ, Qiu ZL, Shen CT, Wei WJ, Luo QY. Pulmonary metastases in differentiated thyroid cancer: efficacy of radioiodine therapy and prognostic factors. Eur J Endocrinol. 2015; 173:399-408. https://doi.org/10.1530/ eje-15-0296.

10. Haugen BR, Alexander EK, Bible KC, Doherty GM, Mandel SJ, Nikiforov YE, Pacini F, Randolph GW, Sawka AM, Schlumberger M, Schuff KG, Sherman SI, Sosa JA, et al. 2015 American Thyroid Association Management Guidelines for Adult Patients with Thyroid Nodules and Differentiated Thyroid Cancer: the American Thyroid Association Guidelines Task Force on Thyroid Nodules and Differentiated Thyroid Cancer. Thyroid. 2016; 26:1133. https://doi.org/10.1089/thy.2015.0020.

11. Schneider DF, Chen H. New developments in the diagnosis and treatment of thyroid cancer. CA Cancer J Clin. 2013; 63:374-94. https://doi.org/10.3322/caac.21195.

12. O'Neill CJ, Oucharek J, Learoyd D, Sidhu SB. Standard and emerging therapies for metastatic differentiated thyroid cancer. Oncologist. 2010; 15:146-56. https://doi. org/10.1634/theoncologist.2009-0190.

13. Ronga G, Filesi M, Montesano T, Di Nicola AD, Pace C, Travascio L, Ventroni G, Antonaci A, Vestri AR. Lung metastases from differentiated thyroid carcinoma. A 40 years' experience. Q J Nucl Med Mol Imaging. 2004; 48:12-9.

14. Kalender E, Zeki Celen Y, Elboga U, Deniz Demir H, Yilmaz M. Lung metastases in patients with differentiated thyroid carcinoma and evaluation of response to radioiodine therapy. Rev Esp Med Nucl Imagen Mol. 2012; 31:328-31. https://doi.org/10.1016/j.remn.2012.04.007.

15. Durante C, Haddy N, Baudin E, Leboulleux S, Hartl D, Travagli JP, Caillou B, Ricard M, Lumbroso JD, De Vathaire F, Schlumberger M. Long-term outcome of 444 patients with distant metastases from papillary and follicular thyroid carcinoma: benefits and limits of radioiodine therapy. J Clin Endocrinol Metab. 2006; 91:2892-9. https:// doi.org/10.1210/jc.2005-2838.

16. Jing C, Huamin G, Baoping L, Guangjun N, Xinli X, Wei C. The relationship between initial $131 \mathrm{i}$ uptake by lung metastases from differentiated thyroid cancer and treatment outcomes. Chin J Nucl Med. 2011; 31:230-2.
17. Qiu ZL, Shen CT, Luo QY. Clinical management and outcomes in patients with hyperfunctioning distant metastases from differentiated thyroid cancer after total thyroidectomy and radioactive iodine therapy. Thyroid. 2015; 25:229-37. https://doi.org/10.1089/thy.2014.0233.

18. Wang RF, Tan J, Guizhi Z, Wei Z, Yajing H, Chengxia L. Curative efficacy and influential factors of $131 \mathrm{i}$ treatment for lung metastases from differentiated thyroid carcinoma. Chin J Nucl Med Mol Imaging. 2015; 35:258-61.

19. Mihailovic J, Stefanovic L, Malesevic M, Markoski B. The importance of age over radioiodine avidity as a prognostic factor in differentiated thyroid carcinoma with distant metastases. Thyroid. 2009; 19:227-32. https://doi. org/10.1089/thy.2008.0186.

20. Sampson E, Brierley JD, Le LW, Rotstein L, Tsang RW. Clinical management and outcome of papillary and follicular (differentiated) thyroid cancer presenting with distant metastasis at diagnosis. Cancer. 2007; 110:1451-6. https://doi.org/10.1002/cncr.22956.

21. Cho SW, Choi HS, Yeom GJ, Lim JA, Moon JH, Park DJ, Chung JK, Cho BY, Yi KH, Park YJ. Long-term prognosis of differentiated thyroid cancer with lung metastasis in Korea and its prognostic factors. Thyroid. 2014; 24:277-86. https://doi.org/10.1089/thy.2012.0654.

22. Hoang JK, Nguyen XV, Davies L. Overdiagnosis of thyroid cancer: answers to five key questions. Acad Radiol. 2015; 22:1024-9. https://doi.org/10.1016/j.acra.2015.01.019.

23. Oh CM, Jung KW, Won YJ, Shin A, Kong HJ, Lee JS. Ageperiod-cohort analysis of thyroid cancer incidence in Korea. Cancer Res Treat. 2015; 47:362-9. https://doi.org/10.4143/ crt.2014.110.

24. Brassard M, Borget I, Edet-Sanson A, Giraudet AL, Mundler O, Toubeau M, Bonichon F, Borson-Chazot F, Leenhardt L, Schvartz C, Dejax C, Brenot-Rossi I, Toubert $\mathrm{ME}$, et al. Long-term follow-up of patients with papillary and follicular thyroid cancer: a prospective study on 715 patients. J Clin Endocrinol Metab. 2011; 96:1352-9. https:// doi.org/10.1210/jc.2010-2708.

25. Heemstra KA, Liu YY, Stokkel M, Kievit J, Corssmit E, Pereira AM, Romijn JA, Smit JW. Serum thyroglobulin concentrations predict disease-free remission and death in differentiated thyroid carcinoma. Clin Endocrinol (Oxf). 2007; 66:58-64. https://doi. org/10.1111/j.1365-2265.2006.02685.x.

26. Wassermann J, Bernier MO, Spano JP, Lepoutre-Lussey C, Buffet C, Simon JM, Menegaux F, Tissier F, Leban M, Leenhardt L. Outcomes and prognostic factors in radioiodine refractory differentiated thyroid carcinomas. Oncologist. 2016; 21:50-8. https://doi.org/10.1634/ theoncologist.2015-0107.

27. Schlumberger M, Challeton C, De Vathaire F, Travagli JP, Gardet P, Lumbroso JD, Francese C, Fontaine F, Ricard M, Parmentier C. Radioactive iodine treatment and external radiotherapy for lung and bone metastases from thyroid carcinoma. J Nucl Med. 1996; 37:598-605. 
28. Ruegemer JJ, Hay ID, Bergstralh EJ, Ryan JJ, Offord KP, Gorman CA. Distant metastases in differentiated thyroid carcinoma: a multivariate analysis of prognostic variables. J Clin Endocrinol Metab. 1988; 67:501-8. https://doi. org/10.1210/jcem-67-3-501.

29. Da M, MA XJ, Shu-Ping LI. A systematic review of the effect of radioiodine-131 in treatment of pulmonary metastases from differentiated thyroid carcinoma and the main prognostic factors. Chin J Endocrinol Metab. 2009; 25:250-4.

30. Castro MR, Bergert ER, Goellner JR, Hay ID, Morris JC. Immunohistochemical analysis of sodium iodide symporter expression in metastatic differentiated thyroid cancer: correlation with radioiodine uptake. J Clin Endocrinol
Metab. 2001; 86:5627-32. https://doi.org/10.1210/ jcem.86.11.8048.

31. Filetti S, Bidart JM, Arturi F, Caillou B, Russo D, Schlumberger M. Sodium/iodide symporter: a key transport system in thyroid cancer cell metabolism. Eur J Endocrinol. 1999; 141:443-57.

32. Hansen LA, Sigman CC, Andreola F, Ross SA, Kelloff GJ, De Luca LM. Retinoids in chemoprevention and differentiation therapy. Carcinogenesis. 2000; 21:1271-9.

33. Pelizzo MR, Boschin IM, Toniato A, Piotto A, Pagetta C, Gross MD, Al-Nahhas A, Rubello D. Papillary thyroid carcinoma: 35-year outcome and prognostic factors in 1858 patients. Clin Nucl Med. 2007; 32:440-4. https://doi. org/10.1097/RLU.0b013e31805375ca. 